\title{
Perencanaan Sistem Drainase Kebon Agung Kota Surabaya, Jawa Timur
}

\author{
Made Gita Pitaloka dan Umboro Lasminto \\ Jurusan Teknik Sipil, Fakultas Teknik Sipil dan Perencanaan, Institut Teknologi Sepuluh Nopember (ITS) \\ Jl. Arief Rahman Hakim, Surabaya 60111 Indonesia \\ e-mail: umboro_hydro@yahoo.com
}

\begin{abstract}
Abstrak-Saluran Kebon Agung terletakdi Surabaya bagian selatan di Kecamatan Jambangan dan bermuara di sisi laut Surabaya bagian Timur di Kecamatan Rungkut. Saluran ini memiliki panjang 11 kilometer dan lebar berkisar antara 7 - 12 meter. Pada saluran Kebon Agung terdapat 2 rumah pompa, yaitu Pompa Kutisari dan Pompa Kebon Agung. Rumah pompa ini sudah berfungsi untuk mengurangi banjir di Surabaya, namun masih kurang maksimal, sehingga masih terjadi genangan di beberapa lokasi. Berdasarkan Peta Kawasan Rawan Banjir Kota Surabaya tahun 2014, terdapat kawasan rawan banjir di pemukiman kampung wilayah kecamatan Jambangan akibat luapan sungai Kali Surabaya. Selain itu, menurut BAPPEKO (Badan Perencanaan Pembangunan Kota) Surabaya tahun 2015, terjadi pula genangan setinggi $10-40 \mathrm{~cm}$ di Kecamatan Wonocolo dan setinggi 10-50 cm di Kecamatan Gununganyar.
\end{abstract}

Perencanaan sistem drainase Kebon Agung dilakukan dengan mengevaluasi kondisi saluran eksisting, kemudian melakukan analisis hidrologi dengan menggunakan program bantu HECHMS untuk mendapatkan debit banjir rencana. Sedangkan, analisis hidrolika menggunakan program bantu HEC-RAS dengan dua kali simulasi unsteady flow, yaitu simulasi kondisi saluran eksisting dan hasil perencanaan.

Berdasarkan hasil analisis kondisi eksisting diperoleh bahwa genangan air terjadi karena kapasitas kapasitas saluran Kebon Agung saat ini tidak dapat mengalirkan debit banjir rencana, sehingga dibutuhkan perencanaan baru. Lebar saluran primer yang diperlukan berkisar antara 8 sampai 15 meter dengan kedalaman 3 meter, lebar saluran sekunder yang diperlukan berkisar antara 5 sampai 8 meter dengan kedalaman 2,5 meter, dan untuk lebar saluran tersier antara 1,2 sampai 2 meter dengan kedalaman 1 meter sampai 2 meter. Jumlah pompa yang dibutuhkan adalah 5 buah pompa dengan kapasitas $5 \mathrm{~m}^{3} /$ detik dan 3 buah pompa dengan kapasitas $1,5 \mathrm{~m}^{3} /$ detik.

Kata Kunci-Drainase, HEC-HMS, HEC-RAS, Kebon Agung

\section{PENDAHULUAN}

$\mathrm{S}$ URABAYA mengalami perkembangan pesat terutama di daerah Surabaya Barat dan Surabaya Timur, ditunjukkan dengan peningkatan pertumbuhan penduduk dan perubahan peruntukan lahan yang semakin cepat. Banyak terjadi perubahan fungsi lahan resapan menjadi bangunan sehingga lahan resapan semakin berkurang. Akibatnya limpasan air hujan banyak yang mengalir di permukaan. Bila hal ini terus terjadi, maka saluran tidak akan mampu menampung limpasan air hujan yang terjadi. Sehingga, air akan meluap ke permukaan dan terjadi genangan.

Berdasarkan Peta Kawasan Rawan Banjir Kota Surabaya tahun 2014 dan BAPPEKO, terdapat kawasan rawan banjir di sejumlah pemukiman kampung wilayah kecamatan Jambangan, kecamatan Wonocolo dan Kecamatan Gununganyar. Bila dibiarkan terus menerus, genangan yang terjadi dapat menimbulkan masalah kesehatan serta mengganggu aktivitas penduduk sekitar. Oleh karena itu, perlu dilakukan perencanaan kembali sistem drainase Kebon Agung agar genangan yang terjadi dapat diatasi.

\section{METODOLOGI}

Metode yang digunakan dalam perencanaan ini adalah sebagai berikut :

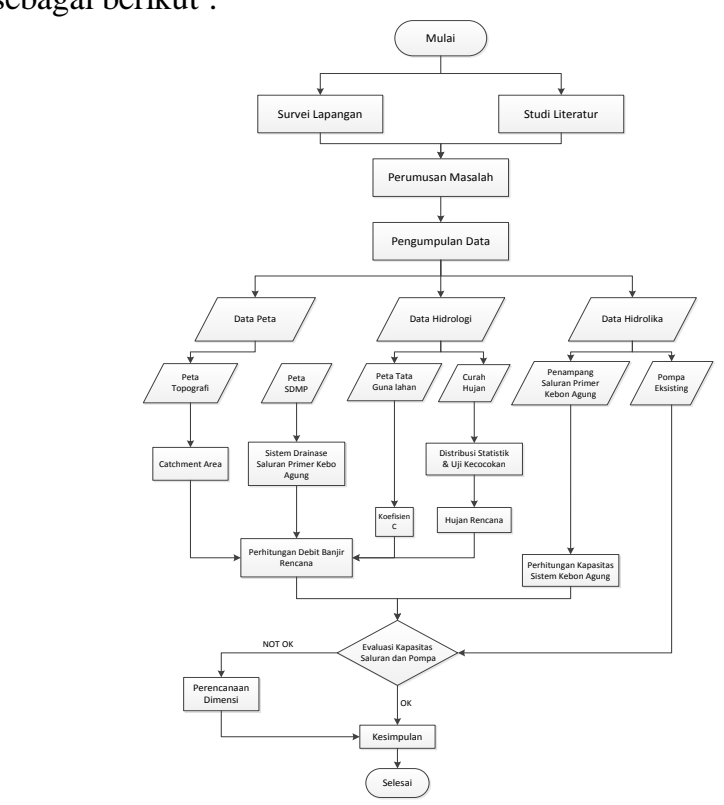

Gambar. 1. Diagram Alir Metodologi

\section{A. Survey Pendahuluan}

Langkah pertama yang dilakukan ialah melakukan pengamatan langsung dilapangan. Hal ini dilakukan untuk mengetahui kondisi eksisting sistem drainase serta mengumpulkan informasi mengenai permasalahan banjir dan genangan. 


\section{B. Analisis Hidrologi}

Selanjutnya, setelah melakukan pengumpulan data, dilakukan analisis hidrologi yang dari penentuan stasiun hujan hingga mendapatkan debit banjir rencana menggunakan program bantu HEC - HMS.

\section{Analisis Hidrolika}

Setelah mendapatkan debit banjir rencana, selanjutnya dilakukan analisis hidrolika hingga didapatkan dimensi saluran rencana beserta bangunan pelengkap menggunakan program bantu HEC - RAS.

\section{HASIL DAN PEMBAHASAN}

\section{A. Analisis Hidrologi}

Analisis hidrologi diperlukan untuk dapat mengetahui secara detail parameter hidrologi dalam kaitannya untuk merancang atau mendesain bangunan air. Pada studi ini analisis hidrologi digunakan untuk menganalisis hujan dan analisis debit rencana. Perhitungan debit banjir menggunakan program bantu HECHMS.

\section{1) Analisis Hujan Rata-rata}

Analisis hidrologi diperlukan untuk dapat mengetahui secara detail parameter hidrologi dalam kaitannya untuk merancang atau mendesain bangunan air. Pada studi ini analisis hidrologi digunakan untuk menganalisis hujan dan analisis debit rencana. Perhitungan debit banjir menggunakan program bantu HECHMS.

Dalam perencanaan drainase kawasan, perlu diketahui besarnya curah hujan yang mewakili kawasan tersebut. Metode yang digunakan untuk perhitungan pada Penelitian ini adalah Metode Poligon Thiessen ${ }^{[1]}$.

Adapun stasiun hujan yang berpengaruh pada sistem drainase Kebon Agung adalah Stasiun Hujan Kebon Agung dan Stasiun Hujan Wonorejo.

Koefisisen Thiessen merupakan hasil dari luas daerah pengaruh masing-masing stasiun hujan dibagi dengan luas daerah total. Berikut merupakan perhitungan Koefisien Thiessen :

$$
\begin{gathered}
W_{\text {Kebon Agung }}=\frac{A_{\text {Kebon } \text { Agung }}}{A_{\text {total }}}=\frac{2269706}{4647142}=0,49 \\
W_{\text {Wonorejo }}=\frac{A_{\text {Wonorejo }}}{A_{\text {total }}}=\frac{2377437}{4647142}=0,51 \\
\text { Tabel } 1 .
\end{gathered}
$$

Rekapitulasi Curah Hujan Rata-Rata Maksimum DAS Kebon Agung

\begin{tabular}{ccc} 
No. & Tahun & R max $(\mathrm{mm})$ \\
\hline 1 & 1994 & 83.164 \\
2 & 1995 & 124.184 \\
3 & 1996 & 71.280 \\
4 & 1997 & 76.303 \\
5 & 1998 & 84.325 \\
6 & 1999 & 103.372 \\
7 & 2000 & 95.465 \\
8 & 2001 & 88.932 \\
9 & 2002 & 110.116 \\
\hline \hline
\end{tabular}

\begin{tabular}{lll}
\hline \hline 10 & 2003 & 91.558 \\
11 & 2004 & 38.907 \\
12 & 2005 & 96.071 \\
13 & 2006 & 54.535 \\
14 & 2007 & 71.420 \\
15 & 2008 & 66.815 \\
16 & 2009 & 51.372 \\
17 & 2010 & 28.372 \\
18 & 2011 & 39.560 \\
19 & 2012 & 95.977 \\
20 & 2013 & 63.023 \\
21 & 2014 & 21.884 \\
\hline \hline
\end{tabular}

(Sumber : Hasil Perhitungan)

\section{2) Analisis Parameter Statistik}

Sebelum dilakukan perhitungan distribusi probabilitas dari data yang tersedia, terlebih dahulu dilakukan penelitian distribusi yang sesuai untuk perhitungan selanjutnya.

Masing-masing distribusi memiliki sifat khas, sehingga setiap data hidrologi harus diuji kesesuaiannya dengan sifat statistik masing-masing tersebut ${ }^{[2]}$. Setiap jenis distribusi atau sebaran mempunyai parameter statistik diantaranya terdiri dari:

$\mathrm{x}$ : nilai rata-rata hitung

$\sigma, S:$ standar deviasi

$\mathrm{Cv}$ : koefisien variasi

$\mathrm{Ck}$ : koefisien ketajaman

Cs : koefisien kemencengan

Perhitungan parameter statistik untuk Distribusi Normal dan Distribusi Gumbel dapat dilihat pada Tabel 2.

Tabel 2.

Perhitungan Parameter Statistik untuk Distribusi Normal dan Distribusi Gumbel

\begin{tabular}{|c|c|c|c|c|c|c|}
\hline No. & Tahun & $\mathrm{R} \mathrm{max}(\mathrm{mm})$ & $(\mathrm{X}-\bar{X})$ & $(\mathrm{X}-\bar{X})^{2}$ & $(\mathrm{X}-\bar{X})^{3}$ & $(\mathrm{X}-\bar{X})^{4}$ \\
\hline 1 & 1994 & 65.793 & -26.658 & 710.641 & -18944.177 & 505011.181 \\
\hline 2 & 1995 & 96.071 & 3.620 & 13.107 & 47.451 & 171.788 \\
\hline 3 & 1996 & 71.093 & -21.358 & 456.167 & -9742.852 & 208088.534 \\
\hline 4 & 1997 & 85.977 & -6.474 & 41.912 & -271.340 & 1756.654 \\
\hline 5 & 1998 & 72.838 & -19.613 & 384.673 & -7544.616 & 147973.122 \\
\hline 6 & 1999 & 98.233 & 5.783 & 33.439 & 193.362 & 1118.134 \\
\hline 7 & 2000 & 112.558 & 20.107 & 404.298 & 8129.276 & 163456.619 \\
\hline 8 & 2001 & 159.462 & 67.011 & 4490.509 & 300914.682 & 20164672.400 \\
\hline 9 & 2002 & 110.116 & 17.665 & 312.056 & 5512.506 & 97379.030 \\
\hline 10 & 2003 & 73.558 & -18.893 & 356.940 & -6743.604 & 127405.870 \\
\hline 11 & 2004 & 80.116 & -12.335 & 152.149 & -1876.747 & 23149.469 \\
\hline 12 & 2005 & 83.164 & -9.287 & 86.247 & -800.974 & 7438.597 \\
\hline 13 & 2006 & 124.184 & 31.733 & 1006.988 & 31954.827 & 1014024.906 \\
\hline 14 & 2007 & 71.420 & -21.030 & 442.276 & -9301.219 & 195607.938 \\
\hline 15 & 2008 & 76.303 & -16.148 & 260.753 & -4210.601 & 67992.145 \\
\hline 16 & 2009 & 84.325 & -8.126 & 66.036 & -536.624 & 4360.744 \\
\hline 17 & 2010 & 103.372 & 10.922 & 119.283 & 1302.778 & 14228.547 \\
\hline 18 & 2011 & 95.465 & 3.014 & 9.087 & 27.391 & 82.569 \\
\hline 19 & 2012 & 95.977 & 3.526 & 12.433 & 43.838 & 154.574 \\
\hline 20 & 2013 & 89.884 & -2.567 & 6.588 & -16.910 & 43.402 \\
\hline 21 & 2014 & 91.558 & -0.893 & 0.797 & -0.712 & 0.635 \\
\hline$\Sigma=$ & 1941.467 & $\sum=$ & 9366.380 & 288135.735 & 22744116.860 \\
\hline $\bar{X}=$ & 92.451 & $\bar{X}=$ & 446.018 & 13720.749 & 1083053.184 \\
\hline
\end{tabular}

(Sumber : Hasil Perhitungan)

$X=\frac{\Sigma X}{n}=\frac{41,076}{21}=1,956 \mathrm{~mm}$ 


$$
\begin{aligned}
s & =\sqrt{\frac{\Sigma(\mathrm{X}-\mathrm{X})^{2}}{n-1}}=S=\sqrt{\frac{9366,380}{21-1}}=21,641 \mathrm{~mm} \\
C_{v} & =\frac{S}{X}=\frac{21,641 \mathrm{~mm}}{92,451 \mathrm{~mm}}=0,234 \mathrm{~mm} \\
C_{s} & =\frac{\Sigma(\mathrm{X}-\mathrm{X})^{\mathrm{a}} \cdot \mathrm{N}}{(n-1)(n-2) S^{\mathrm{a}}} \\
& =\frac{288135,75 \cdot 21}{(21-1) \cdot(21-2) \cdot 21,641^{\mathrm{a}}}=1,571 \\
C_{k} & =\frac{\mathrm{\Sigma}(\mathrm{X}-\mathrm{X})^{4} \cdot n^{2}}{(n-1)(n-2)(n-3) S^{4}} \\
& =\frac{22744116,860^{4} \cdot 21^{2}}{(20) \cdot(19) \cdot(18) \cdot 21,641^{4}}=6,686
\end{aligned}
$$

\begin{tabular}{|c|c|c|c|c|c|c|c|}
\hline No. & Thn & $\begin{array}{c}R \max \\
(\mathrm{mm})\end{array}$ & $\begin{array}{l}\log \\
(\mathrm{X})\end{array}$ & $\begin{array}{r}\log \\
(\mathrm{X} \bar{X})\end{array}$ & $\begin{array}{c}\log \\
(\mathrm{X}-\bar{X})^{2}\end{array}$ & $\begin{array}{c}\text { Log } \\
(\mathrm{X}-\bar{X})^{3}\end{array}$ & $\begin{array}{c}\text { Log } \\
(\mathrm{X}, \bar{X})^{4}\end{array}$ \\
\hline 1 & 1994 & 65.793 & 1.818 & -0.138 & 0.01899 & -0.0026 & 0.0003 \\
\hline 2 & 1995 & 96.071 & 1.983 & 0.027 & 0.00071 & 0.0000 & 0.0000 \\
\hline 3 & 1996 & 71.093 & 1.852 & -0.104 & 0.01085 & -0.0011 & 0.0001 \\
\hline 4 & 1997 & 85.977 & 1.934 & -0.022 & 0.00047 & -0.0000 & 0.0000 \\
\hline 5 & 1998 & 72.838 & 1.862 & -0.094 & 0.00877 & -0.0008 & 0.0000 \\
\hline 6 & 1999 & 98.233 & 1.992 & 0.036 & 0.00131 & 0.0000 & 0.0000 \\
\hline 7 & 2000 & 112.558 & 2.051 & 0.095 & 0.00910 & 0.0008 & 0.0000 \\
\hline 8 & 2001 & 159.462 & 2.203 & 0.247 & 0.06084 & 0.0150 & 0.0037 \\
\hline 9 & 2002 & 110.116 & 2.042 & 0.086 & 0.00737 & 0.0006 & 0.0000 \\
\hline 10 & 2003 & 73.558 & 1.867 & -0.089 & 0.00799 & -0.0007 & 0.0000 \\
\hline 11 & 2004 & 80.116 & 1.904 & -0.052 & 0.00273 & -0.0001 & 0.0000 \\
\hline 12 & 2005 & 83.164 & 1.920 & -0.036 & 0.00130 & -0.0000 & 0.0000 \\
\hline 13 & 2006 & 124.184 & 2.094 & 0.138 & 0.01906 & 0.0026 & 0.0003 \\
\hline 14 & 2007 & 71.420 & 1.854 & -0.102 & 0.01044 & -0.0010 & 0.0001 \\
\hline 15 & 2008 & 76.303 & 1.883 & -0.073 & 0.00540 & -0.0004 & 0.0000 \\
\hline 16 & 2009 & 84.325 & 1.926 & -0.030 & 0.00090 & -0.0000 & 0.0000 \\
\hline 17 & 2010 & 103.372 & 2.014 & 0.058 & 0.00341 & 0.0002 & 0.0000 \\
\hline 18 & 2011 & 95.465 & 1.980 & 0.024 & 0.00057 & 0.0000 & 0.0000 \\
\hline 19 & 2012 & 95.977 & 1.982 & 0.026 & 0.00068 & 0.0000 & 0.0000 \\
\hline 20 & 2013 & 89.884 & 1.954 & -0.002 & 0.00001 & 0.0000 & 0.0000 \\
\hline 21 & 2014 & 91.558 & 1.962 & 0.006 & 0.00003 & 0.0000 & 0.0000 \\
\hline \multicolumn{2}{|c|}{$\Sigma=$} & 1941.46 & 41.07 & $\Sigma=$ & 0.17094 & 0.0124 & 0.0049 \\
\hline \multicolumn{2}{|c|}{$\bar{X}=$} & 92.451 & 1.956 & $\bar{X}=$ & 0.00814 & 0.0005 & 0.0002 \\
\hline
\end{tabular}

Perhitungan parameter statistik untuk Distribusi Log Normal dan Distribusi Log Pearson Tipe III dapat dilihat pada Tabel 3.

Tabel 3.

Perhitungan Parameter untuk Distribusi Log Normal dan Distribusi Log Pearson Tipe III

(Sumber : Hasil Perhitungan)

$$
\begin{aligned}
& \log X=\frac{\sum \log X}{n}=\frac{41,076}{21}=1,956 \mathrm{~mm} \\
& S \log X=\sqrt{\frac{\sum(\log X-\log X)^{2}}{n-1}}=\sqrt{\frac{0,17094}{21-1}}=0,092 \mathrm{~mm} \\
& C V=\frac{S}{X}=\frac{0,092 \mathrm{~mm}}{1,956 \mathrm{~mm}}=0,047
\end{aligned}
$$

$$
\begin{aligned}
C s & =\frac{\Sigma(\log X-\log X)^{a} \cdot N}{(n-1)(n-2) S^{a}} \\
= & \frac{0,0124 \cdot 21}{(21-1) \cdot(21-2) \cdot 0,092^{a}}=0,8717 \\
C k & =\frac{\sum(\log X-\log X)^{4} \cdot n^{2}}{(n-1)(n-2)(n-3) S^{4}} \\
& =\frac{0,0049^{4} \cdot 21^{2}}{(21-1) \cdot(21-2) \cdot(21-3) \cdot 0,092^{4}}=4,3992
\end{aligned}
$$

Sifat khas masing-masing parameter statistik dapat ditinjau dari besarnya nilai koefisien kemencengan (Cs) dan koefisien ketajaman $(\mathrm{Ck})$ yang sesuai dengan syarat dari masing-masing jenis distribusi. Kesimpulan analisis untuk pemilihan jenis distribusi dapat dilihat pada Tabel 4.

Tabel 4.

Kesimpulan Analisis untuk Pemilihan Jenis Distribusi

\begin{tabular}{|c|c|c|c|c|c|c|}
\hline \multirow{2}{*}{ No. } & \multirow{2}{*}{$\begin{array}{c}\text { Metode } \\
\text { Distribusi }\end{array}$} & \multicolumn{2}{|c|}{ Sifat Distribusi } & \multicolumn{2}{|c|}{ Perhitungan } & \multirow{2}{*}{ Keterangan } \\
\cline { 3 - 6 } 1 & Normal & 0 & 3 & 1.571 & 6.6860 & $\begin{array}{c}\text { Tidak } \\
\text { Memenuhi }\end{array}$ \\
\hline 2 & Gumbel & $\begin{array}{c}\leq \\
1.139\end{array}$ & $\leq 5.402$ & 1.571 & 6.6860 & $\begin{array}{c}\text { Tidak } \\
\text { Memenuhi }\end{array}$ \\
\hline 3 & $\begin{array}{c}\text { Log } \\
\text { Pearson } \\
\text { Type III }\end{array}$ & \multicolumn{2}{|c|}{$0<\mathrm{Cs}<9$} & 0.872 & 4.1399 & Memenuhi \\
\hline 4 & $\begin{array}{c}\text { Log } \\
\text { Normal }\end{array}$ & \multicolumn{2}{|c|}{$\mathrm{Cs}=\mathrm{Cv} 3+3 \mathrm{Cv}=3$} & 0.872 & 4.3992 & $\begin{array}{c}\text { Tidak } \\
\text { Memenuhi }\end{array}$ \\
\cline { 3 - 4 } & & \multicolumn{2}{|c|}{$\mathrm{Cs} \neq 0$} & & & \\
\hline
\end{tabular}

(Sumber : Hasil Perhitungan)

Maka, kesimpulan dari Tabel 4, metode distribusi yang memenuhi persyaratan sifat distribusi adalah Metode Distribusi Log Pearson Tipe III.

\begin{tabular}{|c|c|c|c|c|c|c|c|}
\hline \multirow{2}{*}{$\begin{array}{c}\text { Jenis } \\
\text { Distribusi }\end{array}$} & \multicolumn{3}{|c|}{ Uji Chi Kuadrat } & \multicolumn{4}{|c|}{ Uji Smirnov Kolmogorov } \\
\hline & $\mathrm{Xh}^{2}<$ & $X^{2}$ & Ket & D maks & $<$ & Do & Ket \\
\hline $\begin{array}{c}\text { Log Pearson } \\
\text { Type III }\end{array}$ & $2.143<$ & $<$ & OK & 0.036 & $<$ & 0.285 & $\mathrm{OK}$ \\
\hline
\end{tabular}

\section{3) Uji Kecocokan Distribusi}

Uji kecocokan distribusi diperlukan untuk mengetahui apakah data curah hujan yang ada sudah sesuai dengan jenis distribusi yang dipilih, sehingga diperkirakan dapat menggambarkan atau mewakili metode distribusi tersebut.

Pengujian parameter yang dipakai ada $2^{[3]}$, yaitu :

1. Uji Chi-Kuadrat (Chi Square), dan

2. Uji Smirnov-Kolmogorov

Rekapitulasi Uji Chi-Kuadrat, dan Uji SmirnovKolmogorov untuk distribusi Log Pearson Tipe III dapat dilihat pada Tabel 5.

Tabel 5.

Rekapitulasi Uji Kecocokan Distribusi

\section{4) Perhitungan Curah Hujan Periode Ulang}

Perhitungan debit menggunakan metode hidograf satuan sintetis memerlukan data hujan jam-jaman. Lamanya hujan terpusat di Indonesia sendiri tidak lebih dari 7 jam. Hal ini didasari dari Laporan Akhir Departemen Pekerjaan Umum. 
Karena lamanya hujan terpusat di Indonesia yang tidak lebih dari 7 jam, maka direncanakan durasi optimum hujan rencana di wilayah Kota Surabaya sebesar 4 jam.

Tabel 6.

Tinggi Hujan Pada Jam ke-t

\begin{tabular}{|c|c|c|c|c|c|c|c|}
\hline \multirow{2}{*}{ Rt } & \multicolumn{3}{|c|}{ PUH } & \multirow{2}{*}{ Rt' } & \multicolumn{3}{|c|}{ PUH } \\
\cline { 2 - 5 } \cline { 6 - 8 } & 2 & 5 & 10 & & 2 & 5 & 10 \\
\hline Jam & \multicolumn{3}{|c|}{$\mathrm{mm}$} & Jam & \multicolumn{3}{|c|}{$\mathrm{mm}$} \\
\hline 1 & 40.730 & 80.692 & 101.924 & 1 & 40.730 & 80.692 & 101.924 \\
\hline 2 & 25.658 & 50.833 & 64.208 & 2 & 10.586 & 20.974 & 26.492 \\
\hline 3 & 19.581 & 38.793 & 49.000 & 3 & 7.426 & 14.712 & 18.584 \\
\hline 4 & 16.164 & 32.023 & 40.448 & 4 & 5.912 & 11.713 & 14.794 \\
\hline
\end{tabular}

(Sumber : Hasil Perhitungan)

\section{5) Perhitungan Debit Banjir Rencana}

Perhitungan debit banjir rencana dalam Penelitian ini dilakukan menggunakan program bantu HEC-HMS dengan metode US - SCS.

.Adapun beberapa parameter yang diperlukan ${ }^{[4]}$, antara lain :

1. Nama saluran,

2. Kode Saluran/ point,

3. Luas catchment area,

4. Daya serap air (Curve Number), dan kedap air (Impervious),

5. Nilai retensi maksimum (S),

6. Nilai kemiringan lahan (Y),

7. Panjang overland flow (L), dan

8. Time lag $(\mathrm{tL})$.

Output dari program HEC-HMS adalah debit banjir pada masing-masing saluran, digunakan periode ulang 2 tahunan untuk merencakaan saluran tersier dan 5 tahunan untuk saluran primer dan sekunder. Berikut beberapa contoh debit puncak saluran tersier DAS Kebon Agung.

Hasil simulation run ${ }^{[5]}$ untuk saluran tersier PUH 2 tahun, dapat dilihat pada Tabel 7.

Tabel 7.

\begin{tabular}{cc}
\begin{tabular}{c} 
Peak Discharge Saluran Tersier PUH 2 tahun \\
\hline $\begin{array}{c}\text { Hydrologic } \\
\text { Element }\end{array}$
\end{tabular} & $\begin{array}{c}\text { Peak } \\
\text { Dishcarge } \\
\left(\mathrm{m}^{3} / \mathrm{s}\right)\end{array}$ \\
\hline $\mathrm{T}-10$ & 0.8 \\
$\mathrm{~T}-11$ & 0.7 \\
$\mathrm{~T}-12$ & 0.4 \\
$\mathrm{~T}-13$ & 1 \\
$\mathrm{~T}-14$ & 0.6 \\
$\mathrm{~T}-15$ & 0.7 \\
$\mathrm{~T}-16$ & 0.8 \\
$\mathrm{~T}-17$ & 0.9 \\
$\mathrm{~T}-18$ & 0.8 \\
$\mathrm{~T}-19$ & 0.5 \\
$\mathrm{~T}-20$ & 0.6 \\
$\mathrm{~T}-21$ & 0.9 \\
$\mathrm{~T}-22$ & 0.7 \\
$\mathrm{~T}-23$ & 0.9 \\
$\mathrm{~T}-24$ & 1 \\
$\mathrm{~T}-25$ & 0.6 \\
$\mathrm{~T}-26$ & 0.5 \\
$\mathrm{~T}-27$ & 0.7 \\
$\mathrm{~T}-28$ & 0.4 \\
\hline \hline
\end{tabular}

\begin{tabular}{|c|c|}
\hline T-29 & 1.6 \\
\hline T-3 & 2 \\
\hline T-30 & 2 \\
\hline T-31 & 0.7 \\
\hline T-32 & 1.5 \\
\hline T-33 & 1.5 \\
\hline T-34 & 0.8 \\
\hline T-35 & 1.6 \\
\hline T-36 & 3.4 \\
\hline T-37 & 0.1 \\
\hline T-38 & 1.5 \\
\hline T-39 & 0.5 \\
\hline $\mathrm{T}-4$ & 0.5 \\
\hline T-40 & 1 \\
\hline $\mathrm{T}-41$ & 0.7 \\
\hline T-42 & 1.1 \\
\hline $\mathrm{T}-43$ & 0.8 \\
\hline T-44 & 0.9 \\
\hline T-45 & 0.9 \\
\hline $\mathrm{T}-47$ & 0.6 \\
\hline T-48 & 1.2 \\
\hline T-49 & 0.7 \\
\hline T-5 & 0.5 \\
\hline $\mathrm{T}-50$ & 0.8 \\
\hline T-51 & 1.1 \\
\hline T-52 & 0.3 \\
\hline T-53 & 2.6 \\
\hline T-54 & 7.1 \\
\hline T-55 & 4.5 \\
\hline T-56 & 8.4 \\
\hline T-57 & 1.3 \\
\hline T-58 & 0.8 \\
\hline T-59 & 0.4 \\
\hline
\end{tabular}

\section{B. Analisis Hidrolika}

Analisis hidrolika diperlukan untuk merencanakan dimensi penampang saluran. Untuk saluran tersier dilakukan menggunakan perhitungan analitik, sedangkan untuk saluran sekunder dan primer menggunakan program bantu HEC $\operatorname{RAS}^{[6]}$.

\section{1) Analisis Penampang Saluran Tersier}

Penampang saluran tersier DAS Kebon Agung direncanakan menggunakan $U-$ Ditch. $U-$ Ditch adalah saluran dari beton bertulang dengan bentuk penampang huruf $U$ dan juga bisa diberi tutup. Dalam Penelitian ini menggunakan spesifikasi dan dimensi dari PT. Calvary Abadi.

Ketinggian saluran ini dapat bervariasi mengikuti kebutuhan di lapangan atau elevasi yang diinginkan.. Perhitungan dimensi saluran tersier dilakukan dengan menggunakan rumus debit hidrolika ${ }^{[7]}$ :

$$
Q=\frac{1}{n} \cdot R^{2 / a} I^{1 / 2} \cdot A
$$

Perhitungan penampang saluran tersier dilakukan dengan cara trial and error, hingga didapat $\mathrm{Q}_{\text {hidrolika }} \geq \mathrm{Q}_{\text {hidrologi. Maka, }}$ didapatkan hasil perencanaan saluran tersier, beberapa dapat dilihat pada Tabel 8 . 
Tabel 8.

Rencana Tipe $U-$ Ditch Beberapa Saluran Tersier DAS Kebon Agung

\begin{tabular}{ll}
\hline \multicolumn{1}{c}{ Nama Saluran } & Type U - Ditch \\
\hline \hline Sal. Gayung Kebonsari 6 & 20 \\
Sal. Gayung Kebonsari BP & 20 \\
Sal. Gayung Kebonsari Timur & 20 \\
Sal. BRI & 24 \\
Sal. Jemur Andayani 15 & 24 \\
Sal. Kebonsari Baru 1 & 21 \\
Sal. Kebonsari Evelka 4 & 24 \\
Sal. Kebonsari Evelka 4.a & 21 \\
Sal. Dolog & 24 \\
Sal. Gayungsari Barat 3 & 20 \\
Sal. Gayungsari Barat 3.a & 24 \\
Sal. Gayungsari Barat 2 & 20 \\
Sal. Gayung Kebonsari Dalam & 21 \\
Sal. Gayungsari 7 & 21 \\
Sal. Gayungsari 12 & 24 \\
Sal. Gayungsari 13 & 21 \\
Sal. 1.a & 21 \\
Sal. 1.b & 20 \\
Sal. 2.a & 20 \\
Sal. 3.b & 24 \\
Sal. 4.b & 20 \\
Sal. 5.a & 24 \\
Sal. 5.b & 24 \\
Sal. 5.c & 24 \\
Sal. 6.b & 24 \\
\hline \hline : Hail Perhiungan) & 24 \\
\hline
\end{tabular}

(Sumber : Hasil Perhitungan)

\section{2) Analisis Penampang Saluran Primer Eksisting}

Untuk merencanakan dimensi saluran perlu dilakukan evaluasi eksisting terlebih dahulu. Dalam analisis kapasitas saluran DAS Kebon Agung hanya terdapat data saluran primer saja berdasarkan hasil survey, sehingga analisis eksisting hanya dilakukan pada saluran primer . Kapasitas pompa eksisting terdiri dari 3 buah pompa kapasitas 1,5 $\mathrm{m}^{3} / \mathrm{detik}, 2$ buah pompa kapasitas $1 \mathrm{~m}^{3} /$ detik, serta 1 buah pompa kapasitas 0,35 $\mathrm{m}^{3} /$ detik.

Debit banjir yang digunakan merupakan hasil running menggunakan program bantu HEC - HMS, kemudian ditambah $20 \%$ dari $Q$ peak masing - masing saluran sebagai baseflow saluran. Untuk boundary condition merupakan hasil running selama 24 jam, sedangkan untuk initial condition merupakan Q pada jam pertama.

Berdasarkan Gambar 3, dapat dilihat bahwa saluran primer eksisting DAS Kebon Agung tidak dapat mengalirkan debit banjir rencana. Dalam analisis ini dianggap bahwa semua debit banjir datang secara bersamaan sehingga debit banjir rencana menjadi besar sehingga pompa tidak dapat berfungsi dengan maksimal. Oleh karena itu, diperlukan perencanaan saluran kembali.

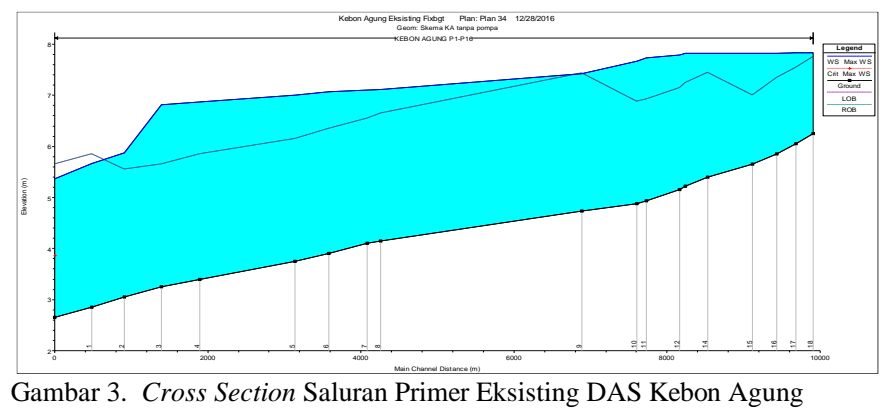

\section{3) Analisis Penampang Saluran Primer dan Sekunder Rencana beserta Bangunan Pelengkap}

Setelah dilakukan analisis eksisting, diperlukan perencanaan saluran kembali. Perencanaan dimensi saluran primer dan saluran sekunder dilakukan dengan menggunakan program bantu HEC - RAS. Penampang yang direncanakan berbentuk persegi empat. Debit banjir yang digunakan merupakan hasil running menggunakan program bantu HEC - HMS kemudian ditambah $20 \%$ dari $Q$ peak masing - masing saluran sebagai baseflow saluran..

Diperoleh hasil seperti yang dapat dilihat pada Gambar 4 untuk cross section saluran primer, Gambar 5 untuk long section saluran primer, Gambar 6 untuk cross section saluran sekunder 11, dan Gambar 7 long section untuk saluran sekunder 11.

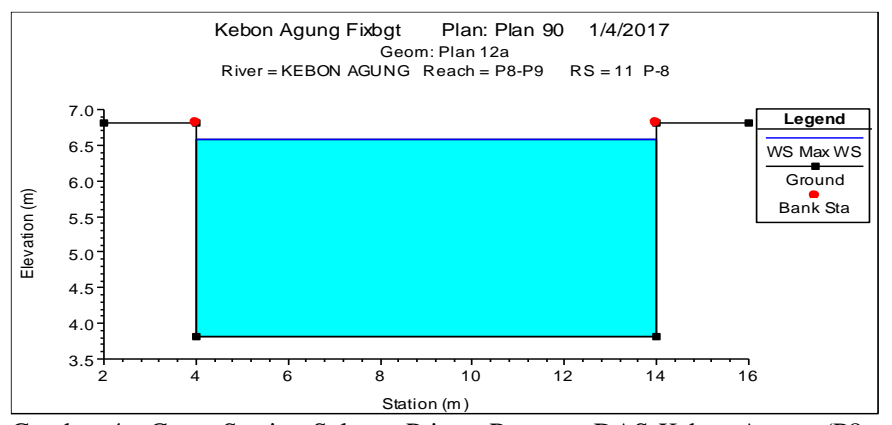

Gambar 4. Cross Section Saluran Primer Rencana DAS Kebon Agung (P8 P9)

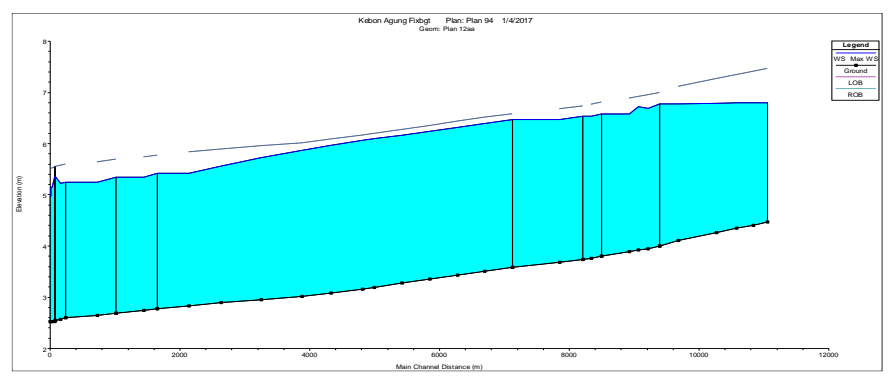

Gambar 5. Long Section Saluran Primer Rencana DAS Kebon Agung (P1 P16) 


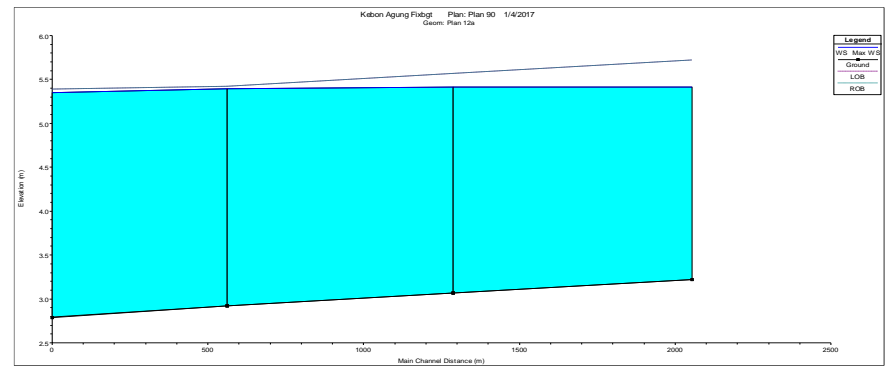

Gambar 7. Long Section Saluran Sekunder Rencana DAS Kebon Agung (Sekunder 11;

\section{KESIMPULAN}

Kesimpulan yang dapat diambil dari penelitian ini adalah sebagai berikut :

1. Genangan air yang terjadi di beberapa tempat pada DAS Kebon Agung terjadi karena kondisi saluran drainase yang kurang terawat, sedimentasi disebagian besar saluran dan dimensi saluran terlalu kecil. Serta, perubahan tata guna lahan dan pemukiman yang menyebabkan berkurangnya RTH sehingga air hujan yg meresap kedalam tanah berkurang dan aliran permukaan meningkat.

2. Berdasarkan hasil analisis hidrologi menggunakan program bantu HEC - HMS, didapatkan debit banjir rencana untuk saluran tersier sebesar $0,2 \mathrm{~m} 3 /$ detik sampai $5,3 \mathrm{~m} 3 /$ detik, untuk saluran sekunder sebesar 1,9 m3/detik sampai 29,3 m3/detik, dan untuk saluran primer memiliki debit banjir rencana terbesar pada hilir sebesar 77,7 m3/detik.

3. Berdasarkan hasil analisis hidrolika, menggunakan program bantu HEC - RAS, diketahui bahwa kapasitas saluran primer eksisting DAS Kebon Agung lebih kecil dari debit banjir rencana, sehingga diperlukan perencanaan saluran kembali. Dengan menggunakan program bantu HEC - RAS, saluran primer direncanakan berbentuk persegi dengan lebar 8 sampai 15 meter, dengan kedalaman 3 meter.

4. Berdasarkan hasil analisis hidrolika, saluran tersier direncanakan menggunakan beton precast U-ditch, dengan lebar 1,2 sampai 2 meter dengan kedalaman 1 meter sampai 2 meter. Sedangkan saluran sekunder direncanakan berbentuk persegi dengan lebar 5 sampai 8 meter dengan kedalaman 2,5 meter. Serta 5 buah pompa dengan kapasitas $5 \mathrm{~m}^{3} /$ detik dan 3 buah pompa dengan kapasitas $1,5 \mathrm{~m}^{3} /$ detik.

\section{DAFTAR PUSTAKA}

[1] Suripin. 2004. Sistem Drainase Perkotaan yang Berkelanjutan. Andi. Yogyakarta.

[2] Soewarno. 1995. Hidrologi Aplikasi Metode Statistik untuk Analisis Data Jilid 1. Nova. Bandung.

[3] Soemarto CD. 1986. Hidrologi Teknik. Surabaya : Usaha Nasional.

[4] Lasminto, Umboro. 2005. Modul Hidrolika: Perencanaan Saluran Terbuka untuk Aliran Seragam. Surabaya..

[5] USACE 2013. HEC - HMS Technical Reference Manual. USA : HEC HMS.

[6] USACE.2010. HEC-RAS Technical Reference Manual. USA : HECRAS

[7] Soemarto CD. 1986. Hidrologi Teknik. Surabaya : Usaha Nasional. 